\title{
MARKETING DE RELACIONAMENTO NA GESTÃO DO FUTEBOL: IDENTIFICAÇÃO E COMPARAÇÃO DAS AÇÕES EM QUATRO CLUBES BRASILEIROS
}

\author{
Ebio Viana Meneses Neto \\ Universidade Federal de Viçosa (UFV) \\ Mestrando em Administração Pública - UFV \\ ebio.meneses1990@gmail.com
}

\author{
Andréia de Fátima Hoelzle Martins \\ Universidade Federal de Viçosa (UFV) \\ Professora Substituta do Departamento de Administração - UFV \\ Doutoranda em Administração - UFV \\ hmartins.andreia@gmail.com
}

\section{Resumo}

Objetivo: O objetivo geral pretendido nesse estudo foi identificar se há uso de instrumentos e estratégias do marketing de relacionamento na gestão dos quatro maiores clubes brasileiros em número de torcedor e comparar as ações entre esses.

Método: É uma pesquisa qualitativa descritiva em que, para atingir os objetivos, utilizou-se de dados secundários como documentos e informações disponíveis nos sites oficiais dos clubes. A partir disso, os dados foram interpretados tentando identificar ações de marketing de relacionamento e sua classificação conforme a literatura.

Originalidade/Relevância: O novo contexto de investimentos no esporte exige maior profissionalização, transparência e racionalização da gestão da área. Assim, estudar as áreas funcionais da administração concatenando com o fato esportivo é de suma importância para práticas mais eficientes e eficazes de gestão, daí a relevância do presente artigo.

Resultados: Dentre os resultados encontrados, destaca-se o programa de sócio torcedor como estratégia de marketing de relacionamento utilizado pelos clubes estudados. Além disso, o modelo de relacionamento contratual foi o mais utilizado pelos clubes.

Contribuições Teóricas/Metodológicas: O conteúdo deste trabalho fornece subsídio para entendimento científico sobre o comportamento do consumidor esportivo e principalmente sobre o processo gerencial dos clubes relacionados ao marketing esportivo e de relacionamento, auxiliando no desenvolvimento de novos trabalhos nesta área.

Contribuições Sociais: O esporte traz consigo aspectos intangíveis, ou seja, o momento esportivo é considerado único e de difícil precificação. Desta forma, o futebol transforma de maneira única a sociedade e este trabalho auxilia no entendimento do torcedor (ente social esportivo) como objetivo central das ações dos clubes.

Palavras-chave: Profissionalização do Esporte. Gestão Esportiva. Consumidor Esportivo. Marketing de Relacionamento.

\section{Cite como}

American Psychological Association (APA)

Meneses, E. V. Neto, \& Martins, A. de F. H. (2020). Marketing de relacionamento na gestão do futebol: identificação e comparação das ações em quatro clubes brasileiros. PODIUM Sport, Leisure and Tourism Review, São Paulo, 9(1), 93-116. https://doi.org/10.5585/podium.v9i1.14512. 


\title{
RELATIONSHIP MARKETING IN SOCCER MANAGEMENT: IDENTIFICATION AND COMPARISON OF ACTIONS IN FOUR BRAZILIAN CLUBS
}

\begin{abstract}
Objective: The general objective intended in this study was to identify whether there are use of relationship marketing instruments and strategies in the management of the four largest Brazilian clubs in number of fans and to compare the actions between them.
\end{abstract}

Method: It is a descriptive qualitative research in which, to achieve the objectives, secondary data such as documents and information available on the official websites of the clubs were used. From that, the data were interpreted trying to identify relationship marketing actions and their classification according to the literature.

Originality/Relevance: The new context of investments in sport requires greater professionalization, transparency and rationalization of the area's management. Thus, studying the functional areas of the administration concatenating with the sporting fact is of paramount importance for more efficient and effective management practices, hence the relevance of this article.

Results: Among the results found, the supporter partner program stands out as a relationship marketing strategy used by the clubs studied. In addition, the contractual relationship model was the most used by clubs.

Theoretical/Methodological Contributions: The content of this paper provides support for scientific understanding of sports consumer behavior and especially about the management process of clubs related to sports and relationship marketing, helping in the development of new works in this area.

Social Contributions: Sport brings with it intangible aspects, that is, the sporting moment is considered unique and difficult to price. In this way, football transforms society in a unique way and this work helps to understand the fans (social sports entity) as the central objective of the clubs' actions.

Keywords: Professionalization of Sport. Sports Management. Sports Consumer. Marketing of relationship.

\section{Introdução}

$\mathrm{O}$ esporte, ou desporto, segundo o dicionário etimológico tem origem francesa e significa "passatempo, recreação, prazer", do verbo desporter, "divertir-se, distrair-se, jogar". O esporte é uma atividade significativa em nossa sociedade, estando diretamente ligado aos maiores eventos do planeta, como a Copa do Mundo ou a Olimpíadas. A dinâmica do esporte traz consigo aspectos relevantes na formação sócio cultural de uma região e infere na política e na economia deste ambiente de inserção (VANCE et al., 2015).

No mundo atual, o esporte está constantemente em destaque por ter conseguido aumentar substancialmente o número de fãs e praticantes, tornando-se alvo de investimentos 
do setor público e privado, através, principalmente, das leis de incentivo e políticas públicas assistencialistas (MELO NETO, 2013).

Dentro do ramo esportivo está o futebol, esporte mais popular e mais praticado em todo mundo. A indústria do futebol movimentou em 2016 aproximadamente 4,3 bilhões somente com os clubes da série A do Campeonato Brasileiro, desde a transferência de jogadores à venda de ingressos e camisas dos clubes (ITAU, 2017).

Já em 2017, a partir do último relatório lançado pelo Itaú (“Análises dos clubes brasileiros"), as receitas dos clubes aumentaram significativamente, muito pela venda de jogadores, que cresceu 55\% em relação à 2016. Entretanto, esse aumento concentrou-se nos clubes de melhor saúde financeira como o Flamengo e Palmeiras (ITAU, 2018).

Estima-se ainda que a final da Copa do Mundo no Brasil tenha sido assistida por 1 (um) bilhão de pessoas ao redor do planeta e um quarto dos brasileiros parou para assistir à sua abertura (GLOBO ESPORTEb, 2015; GLOBO ESPORTE, 2014). Já a final entre Croácia e França, em 2018, teve aproximadamente 1,1 bilhões de espectadores, além de um aumento em todos os jogos de 2,2\% em relação à 2014 (KANTAR IBOPE, 2018). Poucos eventos têm tamanha proporção e transformam em tão pouco tempo o mundo.

Baseado nesses aspectos e no que diz Morgan e Summers (2008), a indústria do futebol e do esporte funciona como mundo do business, demandando práticas de gestão para o seu sucesso. Entretanto, muitos estudiosos da área de Gestão Esportiva têm confrontado os modelos de gestão de clubes brasileiros, pautados pela falta de transparência e negligência ao adotar práticas administrativas (MATTAR, 2014). Estes defendem ainda que a estrutura de associação dos clubes, com gerentes ligados à concepção política, está ultrapassada, principalmente pelo fato que a TV e as leis de incentivo transformaram o futebol em um negócio altamente rentável.

Os clubes de futebol se relacionam de forma mútua com vários públicos e a sobrevivência destes clubes depende inteiramente da gestão dessas inter-relações. Ou seja, sem os consumidores, a mídia, os patrocinadores e o poder público, não haveria futebol (MATTAR, 2014). Assim, a eficiência e eficácia no processo de profissionalizar empreendimentos esportivos não devem acontecer de forma subjetiva, pelo contrário, as decisões no ramo de gestão são medidas pelo nível de desempenho dos desportistas, pela valorização da marca pelos stakeholders ou pelas excelências dos gestores em determinados segmentos esportivos (VANCE; NASSIF; MASTERALEXIS, 2015).

Como parte do processo de profissionalização da gestão do esporte, as técnicas e conceitos das áreas funcionais da administração são levados para o contexto dos clubes brasileiros. Dentre essas, destaca-se o marketing esportivo e o marketing de relacionamento para gerir a relação entre torcedor e clubes de futebol.

O marketing esportivo é o conjunto de ações voltadas à prática e à divulgação de modalidades esportivas, clubes e associações, seja pela promoção de eventos e torneios ou através do patrocínio de equipes e clubes esportivos (BERTOLDO, 2000). Em outras palavras, é uma forma de aproveitar as possibilidades do mercado para incrementar as receitas e o número de clientes fiéis de uma empresa ou produto (MELO NETO, 2013, p.59). O marketing esportivo é a aplicação de estratégias do marketing tradicional na indústria do esporte.

Já o marketing de relacionamento, de acordo com Zenone (2017, p. 48), "é uma ferramenta que busca criar valor pela intimidade com o cliente e tornar a oferta tão adequada, de modo que o cliente prefira manter-se fiel à mesma empresa". Assim, o marketing de relacionamento é relevante para a gestão do futebol, uma vez que a profissionalização busca efetivar o torcedor como um cliente rentável para o clube. 
Kotler e Armstrong (2014) dizem que o marketing de relacionamento não deve ser entendido somente como uma estratégia de venda, mas sim como um método utilizado para satisfazer os desejos e as necessidades dos clientes, de forma que atitudes diferenciadas fortaleçam o relacionamento com os mesmos. Desta forma, além de elaborar estratégias para angariar nova clientela, os clubes devem planejar reter os já existentes, construindo uma relação lucrativa e duradoura.

Acredita-se que a profissionalização da gestão dos clubes e o uso de técnicas e estratégias da administração contribuem para uma gestão financeira positiva e para uma relação mais duradoura e lucrativa entre clube e torcedor (SOUZA, 2005). Neste sentido, a partir de uma análise feita pela BDO que utilizou dados financeiros, pesquisas com o torcedor e principalmente as ações de marketing dos clubes, foi possível identificar que o marketing contribuiu muito para o crescimento (em valor gerado) das marcas dos clubes brasileiros, tendo o Palmeiras, o Corinthians e o Flamengo como os três clubes que mais cresceram nos últimos 5 anos, somando os três aproximadamente 2 bilhões de reais (BDO, 2018, p. 61).

Segundo dados do Datafolha (2018): Clube de Regatas do Flamengo, Sport Club Corinthians Paulista, São Paulo Futebol Clube e Sociedade Esportiva Palmeiras são os quatro maiores clubes em número de torcedores no Brasil. Nesse sentido, o objetivo geral pretendido nesse estudo foi identificar se há uso de instrumentos e estratégias do marketing de relacionamento na gestão desses clubes e comparar as ações entre os clubes, com o intuito de discutir a relevância do marketing de relacionamento no contexto dos clubes de futebol.

Mais especificamente esta pesquisa pretendeu:

a) Identificar e descrever os instrumentos do marketing de relacionamento utilizados pelos quatro maiores clubes em torcedores no Brasil

b) Classificar as ações de marketing de relacionamento encontradas conforme a literatura da área; e

Com isso, pretendeu-se contribuir para a discussão da profissionalização e racionalização da gestão do esporte, especificamente do futebol e dos clubes de futebol brasileiros. Ademais, aproveitou-se para destacar a relevância de trazer a gestão do esporte como conhecimento para a área de administração.

\section{Revisão de literatura}

\subsection{Gestão dos clubes de futebol brasileiros}

A análise da gestão esportiva no Brasil é extremamente complicada. Ao longo dos anos, o desenvolvimento do esporte foi marcado por grandes desigualdades. De um lado existem organizações com práticas administrativas com alto nível de gestão, de outro, organizações sem visão gerencial, expostas com perspectivas extremamente amadoras (VANCE; NASSIF; MASTERALEXIS, 2015, p. 21).

O futebol, assim como o esporte em si, possui características ligadas ao amadorismo, muito em função do topo da pirâmide, ou seja, da alta gerência, que vem desde a criação dos clubes no Brasil (MATTAR, 2014). Este autor ainda diz que, nos dias de hoje, os clubes são reconhecidos como responsáveis pelo futebol profissional, mas essa nomenclatura nem de longe se assemelha ao conceito de profissionalização. De forma geral, os clubes brasileiros possuem uma estrutura limitadora, que impossibilita uma administração eficiente e profissional. Algumas dessas características são: os clubes brasileiros são associações, 
baseadas em gestão voluntária; organograma gerencial complexo; política e disputa por poder; dificuldade em conciliar interesses internos (sócios, conselheiros e etc) com o externo (mercado, governo, patrocinadores, etc).

Pitts (2002) diz ainda que o negócio esportivo sofre interferência de seis ambientes: o ambiente cooperativo, o ambiente competitivo, o ambiente econômico, o ambiente social, o ambiente político e o ambiente legal. É possível destacar que o profissional responsável pela gestão do esporte precisa estudar e compreender bem os ambientes, pois dessa forma conseguirá tomar as decisões de maneira eficaz, a fim de obter o sucesso da empresa e do produto.

Apesar do esporte apresentar um universo alternativo, suas relações não estão fechadas em torno deste, pois elas fazem parte ainda de um sistema de práticas e consumos. Ou seja, existe o estabelecimento de alternativas entre o espaço da oferta e da procura (STAREPRAVO, 2010).

$\mathrm{Na}$ oferta, existe o campo dos programas esportivos, onde se estuda as particularidades e as técnicas do esporte; e na procura destaca-se o espaço das disposições esportivas - que são definidas pela intangibilidade do estado atual da oferta. Neste espaço entra a relação gestãopúblico esportivo (STAREPRAVO, 2010).

Mattar (2014, p. 124) destaca que os públicos relacionados ao futebol (empresas patrocinadoras, consumidores, gestores de carreiras, etc) devem exigir um amadurecimento dos clubes no que tange o uso de práticas administrativas mais eficientes, a fim de profissionalizar o esporte e maximizar os números.

\subsection{Futebol e o marketing esportivo}

O marketing esportivo dentro do futebol pode ser usado como forma de atingir o consumidor esportivo, principalmente pelo fato que o torcedor frequenta os jogos, compra materiais do seu clube e também tem o costume de buscar produtos das empresas patrocinadoras do seu clube de coração.

As definições de marketing esportivo seguem o padrão dos 4P's descritos por Kotler e Armstrong (2014): produto, promoção, praça (distribuição) e preço. Melo Neto (2013, p.74) complementa o modelo com o $5^{\circ}$ (Quinto) P, para adaptar o conceito "Paixão" ao modelo amplamente difundido. $\mathrm{O} \mathrm{P}$ de Paixão refere-se ao comportamento inerente ao principal consumidor esportivo: o torcedor.

Segundo Melo Neto (2013, p.75), o modelo de 5P's voltado para o esporte tem as seguintes definições:

- Produto: Relaciona-se as questões tangíveis (atletas, equipamentos, regras) e, a partir do $5^{\circ} \mathrm{P}$, intangíveis, que são relacionados ao jogo esportivo, caracterizados no âmbito emocional dos clientes.

- Praça: O local jogo é responsável por despertar todo material de confiabilidade do torcedor, o que explica as altas cifras na construção dos palcos esportivos.

- Preço: No âmbito esportivo, o preço assumiu uma nova concepção e valoração. Os valores cobrados pelos produtos, sendo tangíveis e intangíveis, passaram a ser cobrados com relação ao espetáculo, ou seja, ao momento que será vivido pelo cliente. 
- Promoção: A promoção é responsável por estreitar vínculos emocionais dos clientes ou torcedores com seu produto, sendo ele uma agremiação, um atleta ou mesmo um patrocinador.

- Paixão: a emoção ligada ao produto esportivo atinge valores difíceis de mensurar. Portanto, cada momento é considerado único e o gestor esportivo deve entender a importância do cliente para o sucesso do clube.

Vance et al. (2015) dizem que o futebol é o maior responsável pelo crescimento da indústria esportiva no Brasil. Através deste desenvolvimento e também pela busca dos clubes em profissionalizar a sua gestão, a alta cúpula do futebol passou a entender a necessidade de uma administração estratégica em marketing. O torcedor e a promoção do fato esportivo, com o passar dos anos, passou a ser um negócio altamente complexo. Portanto, o gestor esportivo passou a necessitar de novas habilidades para entender o ambiente atual do futebol (VANCE et al., 2015).

O torcedor é parte fundamental de um clube de futebol, ele transforma o marketing de produto e o marketing de serviço, trazendo um ambiente favorável para a indústria do futebol. O cliente esportivo satisfeito, propicia um maior apoio ao clube tanto financeiramente (sócio torcedor) quanto subjetivamente (presença em jogos) (MATTAR, 2014).

\subsection{0 marketing de relacionamento}

Segundo McKenna (1992, p. 3) a partir das constantes alterações no mercado que o desenvolvimento da tecnologia provoca, levando principalmente a fatores como o aumento da competição, várias empresas começaram a alterar o antigo método de voltar-se somente para a produção e passaram a dar enfoque ao cliente e às suas necessidades.

Desta forma, as novas estratégias de marketing passaram a determinar quais são os clientes ou os segmentos que pretendem atuar e de que forma conseguirão criar valor para atender a maior parcela possível deste segmento escolhido, buscando sempre manter um bom relacionamento entre a empresa e o consumidor final (KOTLER, 2014).

Este mesmo autor diz ainda que o processo de marketing passa por três etapas iniciais que são classificadas como construtivas para um bom relacionamento com os clientes, que são: entendimento das necessidades dos clientes; estratégias orientadas para os clientes e um bom programa de marketing. Todas estas impulsionam a quarta e mais importante etapa, a de construir relacionamentos efetivos e duradouros com os clientes (KOTLER, 2014).

Neste sentido, o objetivo principal do marketing de relacionamento é o de construir um relacionamento que seja lucrativo e duradouro, a partir de planejamentos estratégicos que ofereçam a seus clientes uma percepção de valor adequada e além disso satisfação, pois uma premissa básica para fidelização é a satisfação do cliente (ZENONE, 2017; KOTLER, 2014; SILVEIRA, 2010).

Dentre as várias vantagens apresentadas pelo marketing de relacionamento, destaca-se a utilização da estratégia de gestão de relacionamento com o cliente, o CRM. Segundo Zenone (2017) o uso dessa ferramenta permite o desenvolvimento de estratégias de relacionamento que são voltadas ao consumidor final. Este autor ainda diz que o objetivo do CRM é aperfeiçoar os relacionamentos das organizações, e diante disso, proporcionar benefícios para a empresa e para o cliente, de forma que os resultados obtidos sejam lucrativos e o cliente tenha os seus anseios atendidos.

No âmbito esportivo, existem várias formas de identificar o relacionamento entre o cliente (torcedor) e a empresa (clube esportivo). No futebol por exemplo, os fãs, por assim 
dizer, mantém relacionamento com os seus clubes de coração através da compra de materiais esportivos, da presença em espetáculos e através de programas de fidelidade em prol de um futebol melhor (MELO NETO, 2013).

Pensando nas características do consumidor esportivo e em uma forma de desenvolver a confiança e satisfação destes, Berry e Pasuraman (1995) apresentam o que eles conceituam como os "três níveis do marketing de relacionamento":

Nível um: Este nível corresponde ao marketing de Retenção e relaciona-se com as ofertas de benefícios oferecidos ao consumidor. Como exemplo termos os clubes que oferecem afiliação aos seus consumidores em troca de pagamento de taxa ou compra em grande quantidade de produtos do time.

Nível dois: Neste nível o consumidor passa a ser cliente e a relação entre empresa e cliente passa a se tornar um elo social.

Nível três: Neste nível o elo entre empresa e consumidor vai além da compra e relacionamento personalizado.

A execução bem-feita de um marketing de relacionamento proporciona ao clube esportivo o foco total nos melhores clientes, potencializando uma relação duradoura com os mesmos (SILVEIRA, 2010, p.9).

\subsubsection{Estratégias de marketing de relacionamento}

Segundo Kotler (2014, p.13), existem alguns elementos essenciais para que exista um relacionamento duradouro entre empresa e cliente: percepção de valor e satisfação pelo cliente. Atrair e reter clientes passa a ser extremamente difícil se a percepção de valor do cliente com relação ao produto oferecido pela empresa seja abaixo do esperado. Para tanto, o desempenho do produto passa a estar abaixo do esperado e o cliente acaba por ficar insatisfeito.

O CRM, citado anteriormente, auxilia no processo de entendimento do que o cliente espera da empresa. Zenone (2017, p. 70) diz que a gestão de relacionamento do cliente está associada ao marketing, às vendas, aos serviços propostos e à tecnologia envolvida. Todas essas áreas organizacionais, levam o gestor a conhecer os anseios de seus consumidores e então, traçar estratégias, ou programas, interessados na prospecção, fidelização e retenção desses clientes (ZENONE, 2017; SANTOS, 2015).

A prospecção ou pesquisa dos clientes potenciais, está relacionada também com a captação desses clientes. Por meio de pesquisas, as empresas desenvolvem estratégias de marketing que conseguem identificar o posicionamento do mercado e como os consumidores percebem o segmento de atuação da empresa. Isso auxilia também em identificar como o concorrente enxerga esses clientes (SANTOS, 2015). Tendo em mente todos esses dados, é possível: 1 - Identificar diferenças em relação ao concorrente, visando obter vantagem competitiva. 2 - Escolher as vantagens competitivas corretas. 3 - Traçar boas estratégias de posicionamento (KOTLER; ARMSTRONG, 2008).

Essas três características promovem vantagem competitiva sobre os concorrentes, obtida por meio do fornecimento de mais valor para os clientes, seja diminuindo os preços ou oferecendo mais benefícios (KOTLER; ARMSTRONG, 2014, p. 229). Isso é explicado no diagrama de proposições de valor: 
Figura 1 - Matriz Preço x Benefício

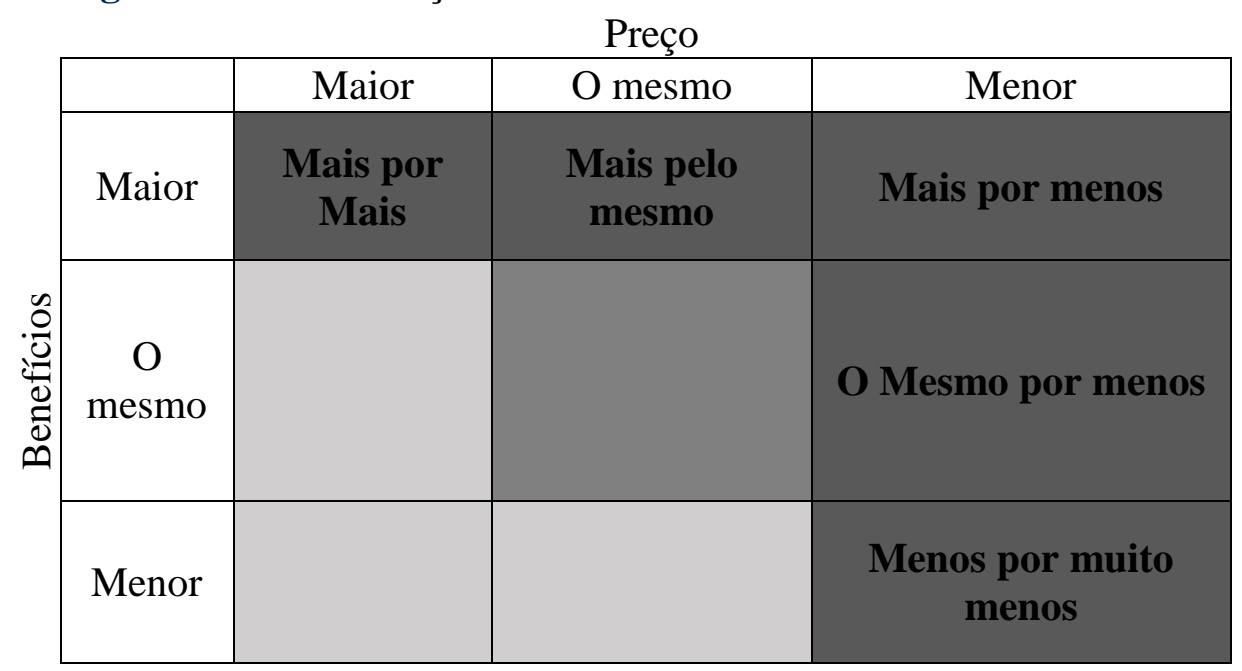

Fonte: Kotler e Armstrong (2014, p. 231).

Este diagrama responde o porquê de o cliente escolher determinada marca para comprar. As células mais escuras representam boas proposições de valor (diferenciação) (KOTLER; ARMSTRONG, 2014, p.231). Após o período de captação, a empresa deverá focar-se em fidelizar/reter os clientes já conquistados. Uma boa gestão de relacionamento com os clientes é capaz de gerar a sua satisfação. Por sua vez, a satisfação em cadeia desperta a fidelidade do cliente, que passa a falar bem da empresa. Assim, o objetivo central da fidelização será atingido, o de encantamento do cliente (KOTLER; ARMSTRONG 2014, p. 20).

Santos (2015), por sua vez, relata que o programa de fidelização por ser dividido em cinco modelos: recompensa, educacional, contratual, afinidade, serviço de valor agregado e alianças ou complementares. O modelo de recompensa busca recompensar os clientes pela sua fidelidade, tentam estimular a compra por meio de incentivos, como prêmios, bônus e pontuações, têm-se como exemplo os cartões de fidelidade (SANTOS, 2015, p.100).

Já o modelo educacional "busca-se manter um ciclo de comunicação interativa com o cliente, fornecendo informações a ele e obtendo em troca respostas que alimentam o banco de dados da empresa" (SANTOS, 2015, p.100). Tal estratégia é geralmente combinada com a abordagem do marketing de conteúdo, que atraído pelas vantagens oferecidas, mantém o relacionamento com o cliente. Esse modelo é utilizado por sites como o "TripAdvisor" ou em casos em que determinada empresa (por exemplo: Hostel), enviam artigos relacionados ao seu negócio para os clientes, como conteúdos sobre turismo, viagem de mochilão, viagens acessíveis, dentre outros temas relacionados com o negócio do hostel. Nesse caso, cliente e empresa relacionam-se e interagem-se pelo conteúdo e informações disponibilizadas.

Quanto ao modelo contratual, consiste na oferta de produtos ou serviços exclusivos ou a preços promocionais para clientes diferenciados. Esse modelo é baseado na segmentação dos clientes - seja conforme fidelidade ou valor dispendido na empresa, em que os clientes mais pontuados ou de maior valor são convidados à benefícios exclusivos. Nesse caso, normalmente se paga uma taxa para se tornar membro e usufruir uma série de benefícios, como eventos ou promoções (SANTOS, 2015; ZENONE, 2017).

Já o modelo de afinidade propõe reunir "grupos de consumidores que compartilham de algum interesse comum relacionado ao produto. Exemplo: o clube de motociclismo da Harley-Davidson" (SANTOS, 2015, p. 101). Conforme exposto por Zanone (2017, p. 72) "geralmente o elemento básico é uma publicação, como revista ou tabloide. A essência de um 
clube de afinidades é a extrema pertinência gerada pelo interesse ou afinidade, trazendo um alto nível de resposta".

Em relação ao modelo de valor agregado (ou adicional) oferece serviços de alto valor para o cliente e o modelo de alianças propõe pacotes promocionais entre empresas coirmãs, ou seja, que possuem produtos complementares, como, por exemplo, a Avianca, "que tem uma parceria com a LocarAlpha, empresa de aluguel de carros" (SANTOS, 2015, p.101).

Esses últimos modelos, dentro do futebol, podem ser visualizados. Podemos citar, por exemplo, o patrocínio entre Adidas e Flamengo. No que concerne o modelo de alianças do Flamengo que, através de seus programas de sócio torcedor, oferece descontos em produtos oficiais adidas como tênis e chuteiras (FLAMENGO, 2018).

Para serem efetivos, os programas de fidelização exigem quatro características básicas para o sucesso das estratégias de relacionamento. Segundo Bogmann (2000, p.91-92), os programas devem: 1- Ter apoio da cúpula. 2- Ter como foco o cliente, sempre. 3- Ser percebidos como uma vantagem competitiva. 4- Ter sua responsabilidade centralizada

Sobre os programas promocionais e vendas, pode-se entender que as empresas não pretendem criar somente clientes lucrativos, elas querem uma relação para vida toda, obtendo a maior parcela possível de participação dos clientes e capturando valor a longo prazo (ZENONE, 2017). Kotler e Amstrong (2014, p.21) complementam ainda, que as empresas pretendem ter um alto customer equity, ou seja, um alto desempenho futuro de vendas, conquistadas a partir do total de valor percebido de todos os clientes da empresa.

Conforme ressaltado por Zenone (2017), muitas são as campanhas de prospecção e fidelização dos clientes, Bretzke (2000) apud Zenone (2017, p.73) elenca sete tipos de campanhas:

1) "Re-sell: Leva o cliente à repetição de compra", como, por exemplo, campanhas que oferecem descontos em uma segunda compra. 2) "Up-sell: incrementa a receita por meio de ações que levem o cliente a comprar categorias de produtos/serviços com maior margem". 3) "Keep-sell: desenvolve ações de retenção quando o database indica propensão a deixar a empresa ou quando existem indicadores do aumento da erosão da base". Exemplo: benefícios para quem renova matrícula, oferta dos mesmos serviços com descontos ou benefícios adicionais. 4) "Add-sell: lançamento de extensões de linhas por meio dos clientes atuais. 5) "New-sell: é o uso do banco de dados de clientes atuais para novos negócios da empresa". Nesse caso, utiliza-se do mesmo público-alvo e banco de dados existente para convidá-los a uma compra diferente do habitual. 6) "Friend-sell: visa transformar clientes em advogados da marca, solicitando indicações ou outro mecanismo amigo". Isso acontece quando são oferecidos descontos para cada amigo indicado que comprar um produto ou serviço. Por exemplo, a Airbnb, quando oferece desconto na próxima hospedagem no caso de um amigo indicado cadastrar no site e fazer uso dos serviços.

A partir dos métodos indicados pelos autores citados anteriormente, percebe-se a variedade de ferramentas e objetivos mais comuns no marketing de relacionamento, de modo que se trabalhe a construção de um relacionamento lucrativo e duradouro. Espera-se que com o uso dessas ferramentas as organizações obtenham ganhos significativos em seu processo de venda, aquisição de parceiros e gestão.

\section{$2.4 O$ marketing de relacionamento e o futebol}

Uma pesquisa desenvolvida por Almeida et al. (2020), mostra a estratégia de Brand Equity baseada nas vendas dos clubes brasileiros como propulsor do desempenho no futebol. Neste trabalho foi tratado o teor empírico dos modelos sobre mensuração do desempenho 
esportivo com o relacionamento entre clube/torcedor. A maioria das ações dos clubes têm viés econômico, mas os efeitos dependem diretamente do quanto o torcedor se relaciona com seu clube (ALMEIDA et al., 2020).

Para elucidar o entendimento sobre a relação marketing de relacionamento e futebol, um case sobre o programa de sócio torcedor do Sport Club Internacional foi desenvolvido por Souza e Lubisco (2006) afim de mostrar a importância do tema para o desenvolvimento de boas práticas no esporte mais popular do brasil.

Segundo o Estatuto Social, o Sport Club Internacional foi fundado em 04 de abril de 1909 por três irmãos da família Poppe, como uma associação sem fins lucrativos. O clube possuía sede em Porto Alegre - Rio Grande do Sul, onde permanece até os dias de hoje (INTERNACIONAL, 2018; SOUZA; LUBISCO, 2006).

O Internacional de Porto Alegre (ou Inter, como também é popularmente conhecido), apesar de não estar entre as maiores torcidas do Brasil, é o clube pioneiro no assunto marketing de relacionamento e programa de sócios torcedores, apresentando em 2018 um contingente de aproximadamente 112 mil sócios torcedores (AMBEV, 2018; INTERNACIONAL, 2018).

É importantíssimo ressaltar, a ênfase que o Internacional dá para a área funcional do marketing. O clube, é um dos poucos que concebe uma "aba" de seu site somente para tratar do marketing esportivo. Diante desta realidade, a agremiação de Porto Alegre considera que "o departamento de marketing tem a missão de promover um processo contínuo de relacionamento e crescimento da marca do Sport Club Internacional, buscando sempre a satisfação plena e o respeito para quem investe em nossas propriedades" (INTERNACIONAL, 2018; SOUZA; LUBISCO, 2006).

O Internacional possui algumas ações de marketing esportivo que se tornaram comuns entre os clubes de futebol: Comercial (Patrocínios e Publicidade); Licenciamento da Marca; Promoções, Eventos e Ações; Locações; Premiações; Ensino/Educação. Já no âmbito do marketing de relacionamento, o programa de sócio torcedor, além de ser pioneiro em modelos no Brasil, se tornou uma das principais fontes de renda do clube (SOUZA; LUBISCO, 2006).

Souza e Lubisco (2006, p5) dizem ainda que o marketing esportivo da maioria dos clubes brasileiros se limita, mesmo atualmente, ao conceito de "marketing de produto", em voga principalmente os patrocínios esportivos. Mas, ao entender melhor o jogo, é possível perceber a importância da relação entre os torcedores e seu clube, de modo que um melhor relacionamento com os mesmos traz um novo conceito para o B2C tradicional.

Segundo Kotler e Armstrong (2014, p.21) o processo de valoração de uma empresa é extremamente importante para o seu público-alvo. O modelo B2C, que envolve o processo de troca de experiência entre a empresa e seu consumidor, tem como aspecto relevante a qualidade do seu produto, a eficiência da operação da empresa, a comunicação e a estratégia de marketing que, basicamente, trará ganho de mercado para o seu negócio, além de aumentar a sua fidelização de clientes.

A partir do case de Souza e Lubisco (2006) e apropriando-se dos conceitos amplamente difundidos por Kotler e Armstrong (2014), destaca-se o uso de estratégias de marketing por parte do Internacional com enfoque nos P's de produto (para a valorização da marca) e paixão (emocional e fidelização). Desta forma, é de suma importância identificar se o mesmo acontece para outros clubes para reafirmar a teoria. 


\section{Metodologia}

3.1 Tipo de pesquisa

O estudo tem natureza qualitativa, por objetivar identificar, descrever e comparar as ferramentas do marketing de relacionamento dos quatro maiores clubes do Brasil em torcida, analisando qualitativamente a relação entre as estratégias utilizadas e o número de sociotorcedores. Os dados analisados também foram qualitativos. Segundo Bignardi (2003), a metodologia qualitativa permite o autor mergulhar na profundidade dos fenômenos estudados levando em consideração toda sua particularidade.

A pesquisa possui caráter descritivo, visando atender o objetivo proposto, o de identificar e descrever os instrumentos do marketing de relacionamento utilizados pelos quatro maiores clubes em número de torcedores no Brasil. Segundo Gil (2002, p.42) as pesquisas descritivas têm como objetivo descrever características pontuais de populações, fenômenos ou mesmo relatar o estabelecimento de relações entre variáveis. Este trabalho se propõe a descrever o nível de relacionamento entre os clubes de futebol e seus torcedores, a fim de propor medidas para uma gestão profissional no âmbito de marketing de relacionamento.

Na coleta de dados foram utilizados dados secundários presentes nos sites oficiais dos clubes de futebol, artigos publicados em revistas, jornais e sites especializados, além de livros e relatórios anuais dos clubes, dos quais foi possível observar dados e informações relevantes ao objetivo da pesquisa quanto à atuação dos clubes com relação ao marketing de relacionamento. Segundo Marconi e Lakatos (2003), os dados secundários são "os dados que já se encontram disponíveis, pois já foram objeto de estudo e análise"

A análise dos dados visou responder aos dois objetivos específicos propostos. A estrutura da apresentação dos resultados visou identificar as ações e descrever as estratégias de marketing esportivo dos quatro maiores clubes em número de receitas. Tal estrutura consiste em: Exposição de Ações e descrição das ações de cada clube e comparação das ações identificadas.

Adicionalmente, a partir dos dados coletados, visou-se discutir a relação entre ações desenvolvidas e número de sócio torcedores, tendo em vista que, espera-se, que as ações de marketing de relacionamento impactem o cenário (em número, percepção sobre o valor de ser sócio) de sócio torcedores do clube. Os dados coletados são os mais atuais e correspondem ao ano de 2018, ano do último balancete dos clubes estudados.

A escolha dos quatro clubes abaixo relacionados foi feita de forma intencional, sendo, além disso, os clubes de maiores torcidas em números no futebol brasileiro. São eles:

Quadro 1 - Variações x Clube

\begin{tabular}{|l|c|c|c|c|}
\hline \multicolumn{1}{|c|}{ Variações/Clube } & Flamengo & Corinthians & São Paulo & Palmeiras \\
\hline $\begin{array}{l}\text { Número de } \\
\text { Torcedores }\end{array}$ & $\begin{array}{c}+-33 \text { milhões } \\
\text { (DATAFOLHA, 2018) }\end{array}$ & $\begin{array}{c}+-27,3 \text { milhões } \\
\text { (DATAFOLHA, } \\
2018)\end{array}$ & $\begin{array}{c}+-13,6 \text { milhões } \\
\text { (DATAFOLHA, } \\
2018)\end{array}$ & $\begin{array}{c}+-10,6 \text { milhões } \\
\text { (DATAFOLHA, } \\
2018)\end{array}$ \\
\hline $\begin{array}{l}\text { Número de Sócios } \\
\text { Torcedores }\end{array}$ & +-92 mil (FLAMENGO, & $\begin{array}{c}+-118 \mathrm{mil} \\
\text { (AMBEV, } \\
2018)\end{array}$ & $\begin{array}{c}\text { (AMBEV, } 154 \mathrm{mil} \\
\text { 2018) }\end{array}$ & $\begin{array}{c}\text { +- } 130 \mathrm{mil} \\
\text { (AMBEV, } \\
2018)\end{array}$ \\
\hline
\end{tabular}

Fonte: Elaborado pelos autores (2018) 


\section{Resultados e discussões}

\subsection{Ações de marketing de relacionamento dos clubes de futebol}

Visando atender aos dois objetivos propostos, optou-se pela estrutura de apresentação que segue. Algumas fontes estatísticas são retiradas do Datafolha (2018) por se tratar de um órgão que ao longo dos anos se comprometeu a levantar dados relacionados às torcidas brasileiras.

Pretendeu-se discutir as ações de marketing de relacionamento dispostas nos sites oficiais dos clubes através da literatura exposta no referencial teórico. Os quadros a seguir foram elaborados pelo autor e buscam elucidar para um melhor entendimento dos objetivos propostos. A seguir, as ações de cada clube:

\subsubsection{Clube de Regatas do Flamengo}

O Clube de Regatas Flamengo tem a Missão de "Ser um clube formador de talentos esportivos (...) trazendo resultados esportivos relevantes aos seus torcedores" e a Visão "Ser o maior e melhor time de futebol das Américas e um dos 10 maiores clubes de futebol do mundo (...) e o melhor no plano esportivo..." (FLAMENGO, 2018).

A seguir são expostas as ações de marketing de relacionamento desenvolvidas pelo clube:

Quadro 2 - Ações Flamengo

\begin{tabular}{|c|c|l|}
\hline Ações & Classificação & \multicolumn{1}{c|}{ Breve Descrição } \\
\hline $\begin{array}{c}\text { Programa Escola de } \\
\text { Esportes "Sempre } \\
\text { Flamengo" }\end{array}$ & $\begin{array}{l}\text { A Escola de Esportes Sempre Flamengo segue crescendo e desenvolvendo } \\
\text { campeões, revelando talentos e, acima de tudo, formando cidadãos. Além } \\
\text { de todos os valores da prática esportiva, os destaques das turmas ainda } \\
\text { Contratual } \\
\text { podem se tornar federados e defenderem as equipes de base do Flamengo. } \\
\text { Para serem alunos da Escola de Esportes, os pequenos podem se tornar } \\
\text { Sócios Contribuintes mesmo sendo menores de idade, adquirindo o direito } \\
\text { de frequentar o clube até nos dias em que não tem aula. }\end{array}$ \\
\hline $\begin{array}{c}\text { Programa de Sócio- } \\
\text { Torcedor: "Nação } \\
\text { Rubro-Negra" }\end{array}$ & $\begin{array}{l}\text { O "Nação Rubro-Negra" foi desenvolvido em 2013, no mandato do } \\
\text { presidente Eduardo Bandeira de Melo, pelo departamento de marketing do } \\
\text { clube com a ajuda da empresa Golden Goal. Os planos desenvolvidos } \\
\text { Contratual } \\
\text { foram batizados de Raça, +Raça, Amor, +Amor, Paixão e +Paixão } \\
\text { Membros do quadro social do clube interessados precisarão fazer adesões } \\
\text { à parte e sem nenhum tipo de benefício extra. O Programa sofre alterações } \\
\text { constantemente a partir da segmentação dos torcedores. }\end{array}$ \\
\hline
\end{tabular}

Fonte: Elaborado pelos autores com base nos resultados da pesquisa (2018).

O Programa Escola de Esportes "Sempre Flamengo" é oferecido para todos os sócios contribuintes do clube Flamengo que desejam se desenvolver a partir da prática esportiva. $\mathrm{O}$ sócio contribuinte, de acordo com o estatuto social disponível em Flamengo (2018), "é o associado admitido a este título no quadro associativo", ou seja, é aquele que contribui financeiramente para usufruir das dependências e das atividades oferecidas pelo clube. Se difere do sócio torcedor, pois além do direito à voto, tem direitos e deveres que não só o pagamento mensal da contribuição.

Partindo deste pressuposto, é notório que o programa Escola de Esportes partilha do conceito de modelo contratual de fidelização descrito por Santos (2015), em que o Flamengo oferece aos contribuintes vários benefícios compensatórios e firmados em contrato (SANTOS, 2015; ZENONE, 2017). 
Outra atividade ligada diretamente ao marketing de relacionamento do Clube de Regatas do Flamengo é o Programa "Nação Rubro-Negra". O Flamengo atualiza constantemente o seu programa de sócio torcedor, visando uma maior prospecção e fidelização dos seus torcedores, compondo os níveis 1 e 2 conceituados por Berry e Pasuraman (1995).

As estratégias mais robustas de marketing de relacionamento propostas pelo Clube de Regatas do Flamengo estão associadas ao programa "Nação Rubro-Negra". Os planos oferecidos são os seguintes:

O Plano Paixão, + Paixão, Amor, + Amor, Raça, + Raça, Onde Estiver e Nação Jr. Quanto maior o valor pago, maiores são os benefícios dos planos. Nesse sentido, pode-se perceber no programa as principais características do modelo contratual descrito por Santos (2015) e Zenone (2017), em que sob uma taxa fixa o cliente acessa os benefícios previsto para aquela categoria. As categorias normalmente variam de mais benefícios a menos benefícios conforme a variação de preço da taxa.

A criação do Plano "Onde Estiver" aconteceu a partir de uma análise feita pelos gestores do clube: a prospecção de sócios-torcedores estava sendo feita de maneira equivocada, principalmente pelo fato que a torcida Rubro-Negra fora do Rio de Janeiro é a maior entre todos os clubes, conforme mostra a pesquisa do Datafolha (2018).

O plano Nação-Jr visa atingir torcedores menores de 14 anos, no qual essas crianças e pré-adolescentes têm acesso à carteirinha personalizada, kit de boas-vindas e experiências exclusivas. Os benefícios desse plano são compatíveis com os interesses do público do plano e tenta ser atrativo por meio de experiências elaboradas para essas crianças (FLAMENGO, 2018).

Além disso, de uma forma geral, a fidelização do programa "Nação Rubro-Negra" visa premiar os torcedores mais participativos em jogos e compra de produtos oficiais do clube (FLAMENGO, 2018). Nesse sentido, embora seja um programa classificado dentro do modelo contratual, esse utiliza da estrutura do modelo de recompensa para incentivar o pagamento em dia pelos sócios torcedores. Enquanto os programas de modelo de recompensa incentivam uma nova compra, trabalhando dentro do tipo "Re-sell", conforme denominado por Zenone (2017), o programa recompensa os sócios torcedores conforme seu grau de assiduidade.

É visível o foco do Clube de Regatas do Flamengo no programa de sócio torcedor. Além de ser o carro chefe, ele tem ações limítrofes ao balanço financeiro do clube, possibilitando um maior investimento ao esporte principal: o Futebol. O grande desafio do clube é conciliar o lado emocional e o racional dos torcedores, isto é, fazer com o que o torcedor seja associado agregando as vantagens e os custos, o que mostra a importância do marketing de relacionamento nesse caso.

\subsubsection{Sport Club Corinthians}

Melo Neto (2013) cita a paixão como uma mola que impulsiona o cliente desportivo. De fato, o torcedor corintiano (aproximadamente 30 milhões de "fiéis torcedores") é conhecido pela sua fidelidade e fanatismo pelo clube. Algumas mudanças ocorridas na estrutura organizacional do Sport Club Corinthians, mostra uma relevância maior ao seu torcedor.

Além dessas alterações, o Corinthians passou a investir significativamente em campanhas de marketing esportivo. Os gestores responsáveis criaram lojas oficiais, lançaram filmes e documentários sobre o clube e sua torcida, focaram em campanhas publicitárias a fim 
de angariar patrocínios pontuais (CORINTHIANS, 2018). Após planejar todas as estratégias de crescimento e valorização da marca, o Corinthians voltou suas ações para o relacionamento com o torcedor. Assim, em 2008, foi criado o programa "Fiel Torcedor", programa de sócio torcedor com o foco em aproximar ainda mais o clube com seus torcedores, proporcionando assim benefícios de forma mútua (SPORT CLUB CORINTHIANS PAULISTA, 2018).

A seguir são expostas as ações de marketing de relacionamento desenvolvidas pelo clube:

Quadro 3 - Ações Corinthians

\begin{tabular}{|c|c|c|}
\hline Ações & Classificação & Breve Descrição \\
\hline $\begin{array}{l}\text { Programa } \\
\text { "Loucos por } \\
\text { Pontos" }\end{array}$ & $\begin{array}{c}\text { Modelo } \\
\text { Recompensa } \\
\text { (Re-sell) }\end{array}$ & $\begin{array}{l}\text { O Programa Louco por Pontos foi criado para fornecer benefícios para todos } \\
\text { os torcedores do Corinthians. O Programa leva o conceito de fidelidade em } \\
\text { troca de descontos em lojas parceiras, benefícios gratuitos, recompensas } \\
\text { exclusivas a partir de pontos acumulados através de um cadastro e compras } \\
\text { em lojas conveniadas }\end{array}$ \\
\hline $\begin{array}{c}\text { Programa "Loko } \\
\text { da Fiel" }\end{array}$ & $\begin{array}{c}\text { Modelo } \\
\text { Educacional }\end{array}$ & $\begin{array}{l}\text { O Primeiro torcedor virtual do mundo. O Programa "Loko da Fiel" foi criado } \\
\text { para o torcedor corinthiano que pretende discutir futebol, além de conhecer } \\
\text { todas as histórias e ações do clube do coração, sem sair de casa. O torcedor } \\
\text { consegue manter uma conversação } 24 \text { horas com uma inteligência artificial, } \\
\text { que visa fortalecer a marca Corinthians. }\end{array}$ \\
\hline $\begin{array}{c}\text { Programa de } \\
\text { Sócio-Torcedor : } \\
\text { "Fiel Torcedor" }\end{array}$ & $\begin{array}{c}\text { Modelo } \\
\text { Contratual }\end{array}$ & $\begin{array}{l}\text { Em } 2008 \text { o clube iniciou o sistema de fidelização onde o sócio torcedor teria } \\
\text { vantagens de compra antecipada de ingressos pela internet e privilégios para } \\
\text { os mais assíduos. Atualizado em } 2018 \text {, o programa conta com quatro opções } \\
\text { de planos, sendo elas: o Plano Minha Vida, Plano Minha História, Plano Meu } \\
\text { Amor e o Plano Minha Cadeira. Cada um possui valor e benefícios diferentes. }\end{array}$ \\
\hline
\end{tabular}

Fonte: Elaborado pelos autores com base nos resultados da pesquisa (2018).

O Programa "Louco por Pontos" é um modelo de marketing de relacionamento do Corinthians que visa recompensar os corintianos que buscam comprar sempre nas lojas oficiais e nos parceiros (patrocinadores e empresas conveniadas).

Neste sentido, o "Loucos por Pontos" atua no modelo de recompensas (SANTOS, 2015), pois o clube tenta recompensar os torcedores por sua fidelidade, oferecendo pontos que posteriormente serão trocados em descontos em outros produtos ou por benefícios como camisas oficiais e ingressos de jogos. Este tipo de campanha leva os torcedores a comprarem novamente, visando acumular a maior quantidade de pontos, seguindo o modelo "Re-sell" de campanha (ZENONE, 2017).

O Programa "Loko da Fiel" é uma estratégia inovadora entre todos os clubes do brasil, na qual o Sport Club Corinthians utiliza de inteligência artificial visando fortalecer a marca Corinthians entre seus torcedores e angariar possíveis patrocinadores a partir de uma união entre marketing esportivo e de relacionamento. O Loko é um torcedor virtual que conversa com os torcedores e mostra bastidores dos jogos, faz campanhas publicitárias de todos os programas e ainda responde em chat dúvidas sobre o Corinthians. Desta forma, podendo ser classificado como um programa de modelo educacional (SANTOS, 2015).

As estratégias de marketing de relacionamento baseadas no modelo educacional têm o objetivo de trocar constantemente informações a partir dos clientes, podendo traçar o perfil destes e consequentemente estreitar a relação entre empresa/cliente (SANTOS, 2015).

O programa de sócio torcedor "Fiel Torcedor" segue os moldes do programa Nação Rubro-Negra do Flamengo e classifica-se como modelo contratual (SANTOS, 2015), podendo acumular ganhos financeiros em troca de benefícios para os participantes do programa. As estratégias mais robustas de marketing de relacionamento propostas pelo Sport 
Club Corinthians estão associadas ao programa "Fiel Torcedor". Os planos oferecidos são "Minha Vida", "Minha História", "Meu amor" e "Minha cadeira".

Do mesmo modo que nos outros programas contratuais, o sócio torcedor do Corinthians acessa mais ou menos benefícios conforme o preço da taxa mensal paga ao clube. Através do Fiel Torcedor o sócio pode ajudar o Corinthians de várias formas, sendo direta e indiretamente. Em contrapartida, o clube tem o objetivo de retribuir esta ajuda através de benefícios oferecidos. Comparando o que diz Kotler e Armstrong (2014) sobre marketing de relacionamento e fidelização da marca com as estratégias adotadas pelo Sport Club Corinthians Paulista, fica clara a relação da teoria com o objetivo do Programa "Fiel Torcedor" proposto pelo clube:

O Sport Club Corinthians oferece aos seus associados benefícios que o dinheiro não pode comprar: Tem preço conhecer o treinador, atletas, instalações, participar de entrevistas coletivas e muitas outras ações? O Fiel Torcedor proporciona isso aos seus sócios! O programa Fiel Torcedor está subdividido planos, visando atender a toda Nação Corinthiana e levando em consideração todos os perfis de torcedores. (Sport Clube Corinthians Paulista, 2018).

\subsubsection{São Paulo Futebol Clube}

Segundo o estatuto social do São Paulo Futebol Clube, a diretoria do clube deve ser responsável por traçar estratégias específicas de gestão e publicidade, além de criar um regulamento próprio para definir os critérios de relacionamento comercial do SPFC com os torcedores que integram o programa de sócio torcedor (SÃO PAULO FC, 2017).

Além disso, o texto aprovado pelo Conselho de Administração disciplinará preços, direitos, obrigações e sanções para os vinculados ao programa, bem como manter relação com empresas parceiras de fornecimento de produtos específicos como ingressos e produtos oficiais do clube (SÃO PAULO FC, 2017).

Várias ações do clube, mostram a significância de um marketing de relacionamento bem feito. Zenone (2017) diz sobre a necessidade de criar relações duradouras entre as empresas e os clientes, sendo esta parte relacionada aos métodos de propaganda e venda.

A seguir são expostas as ações de marketing de relacionamento desenvolvidas pelo clube: 
Quadro 4 - Ações São Paulo

\begin{tabular}{|c|c|c|}
\hline Ações & Classificação & Descrição \\
\hline Patrocínio "Master" & $\begin{array}{l}\text { Modelo de valor } \\
\text { agregado ou } \\
\text { adicional }\end{array}$ & $\begin{array}{l}\text { Parceria entre o São Paulo e o Banco Inter, em que o Banco Inter } \\
\text { passou a desenvolver uma série de ações e ativações com o clube, } \\
\text { como o cartão de crédito customizado para o São Paulo e seus } \\
\text { torcedores, cujas transações rendem um percentual para o clube. }\end{array}$ \\
\hline $\begin{array}{l}\text { "Viaje com o } \\
\text { Tricolor" }\end{array}$ & $\begin{array}{c}\text { Produto } \\
\text { Experiência }\end{array}$ & $\begin{array}{l}\text { Florida Cup 2019. O programa busca torcedores que estão dispostos } \\
\text { a pagar para viajar com o São Paulo para Orlando. O objetivo é } \\
\text { acompanhar a pré-temporada no seu clube de coração e passar } \\
\text { momentos inesquecíveis. }\end{array}$ \\
\hline $\begin{array}{l}\text { "Vou jogar no } \\
\text { Morumbi" }\end{array}$ & $\begin{array}{c}\text { Produto } \\
\text { Experiência }\end{array}$ & 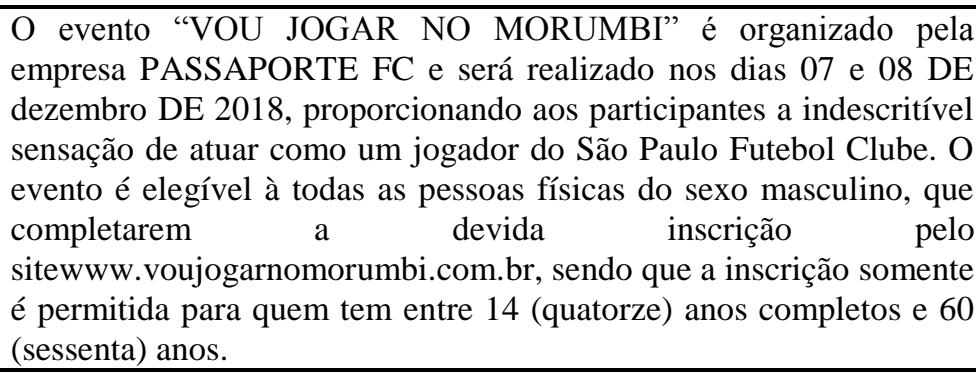 \\
\hline $\begin{array}{c}\text { Programa de Sócio } \\
\text { Torcedor }\end{array}$ & Modelo Contratual & $\begin{array}{l}\text { A maior vantagem que um são-paulino tem ao se associar Programa } \\
\text { Sócio Torcedor é ajudar a construir um time e um clube cada vez } \\
\text { mais fortes. Mas não é só isso, você fará parte de um time de } \\
\text { torcedores que poderá estar mais próximo do time do coração, com: } \\
\text { Descontos e preferência na compra de ingressos antecipados; } \\
\text { Participação e promoções e experiências exclusivas; Clube de } \\
\text { vantagens e moedas tricolores; Descontos em parceiros comerciais. } \\
\text { Ranking de preferência para a compra antecipada de ingressos }\end{array}$ \\
\hline
\end{tabular}

Fonte: Elaborado pelos autores com base nos resultados da pesquisa (2018).

O relacionamento entre o São Paulo e o Banco Inter começou em janeiro de 2017, quando ainda se chamava Intermedium. Em pouco tempo, mais precisamente em maio do mesmo ano, a Intermedium tornou-se a patrocinadora master do clube, estampando a sua marca nos uniformes de futebol (SPFC, 2018).

O contrato com o Banco Inter irá até 2020 e para um relacionamento sadio, além da exposição na camisa, o Banco passou a desenvolver uma série de ações e interações com o clube. A relação entre o São Paulo e o Banco Inter pode ser classificada dentro do modelo de valor agregado (SANTOS, 2015), em que uma ou mais empresas unem-se para oferecer serviços diferenciados ou promoções específicas para os clientes, beneficiando tanto os clientes, quanto as empresas envolvidas.

O Programa "Viaje com o Tricolor" embora assemelha-se à troca, característica do modelo contratual (em que se paga uma taxa para adquirir benefícios), esse não é classificado como tal porque trata-se de uma ação pontual condicionada a um preço, que não é semelhante a uma taxa mensal ou anual para o usufruto de benefícios durante aquele tempo. Nesse sentido, classificamos o programa como um produto ou "Produto Experiência" que pode ser entendido como uma ação de marketing de relacionamento, tendo em vista que se trata de um produto do São Paulo que tem em seu diferencial a aproximação entre torcedor e clube a partir da experiência prometida pelo produto.

O Programa "Vou jogar no Morumbi" funciona de forma parecida com o "Viaje com o Tricolor" e, por isso, também foi classificado como "Produto Experiência". Este programa, além de ir ao encontro do modelo contratual do marketing de relacionamento, possui também ações particulares de marketing esportivo. 
Além disso, o São Paulo possui o programa de sócio torcedor do clube, que se classifica como um modelo contratual (SANTOS, 2015). Os planos oferecidos são: "sou tricolor", "vamos são Paulo", "o mais querido", "clube da fé", "tu és forte", "tu és grande", "tu és primeiro" e "são Paulo brasil".

O programa sócio torcedor possui oito diferentes planos, sendo um deles exclusivo para torcedores que residem fora do estado de São Paulo e que não frequentam o estádio do Morumbi. O carro chefe do programa sócio torcedor são paulino são os descontos na compra de ingressos em todos os setores do estádio, exceto cadeiras cativas e setor visitante ( $\mathrm{S} \tilde{\mathrm{A} O}$ PAULO FC, 2017).

O São Paulo Futebol Clube, utiliza estratégias do "P" de Paixão para os seus sóciostorcedores, fornecendo momentos únicos, intangíveis e imprevisíveis. As estratégias de marketing de relacionamento são muito presentes, o que mostra um modelo de gestão extremamente inteligente e profissional.

\subsubsection{Sociedade Esportiva Palmeiras}

O Palmeiras teve na temporada de 2017 um faturamento acima do meio bilhão de reais. Deste, 47 milhões foram decorrentes do programa de sócio torcedor "Avanti", para um valor médio de 120 mil sócios torcedores (SE PALMEIRAS, 2018). O faturamento total foi o suficiente para que o clube pagasse todos os investimentos que fez na folha salarial e na aquisição novos jogadores, e ainda sobrasse um superávit de $\mathrm{R} \$ 57$ milhões.

O Presidente Galliote acredita que com um ticket médio de 220 mil sócios torcedores, o clube conseguirá arcar com todas as despesas do futebol. A seguir são expostas as ações de marketing de relacionamento desenvolvidas pelo clube:

Quadro 5 - Ações Palmeiras

\begin{tabular}{|c|c|l|}
\hline Ações & Classificação & \multicolumn{1}{c|}{ Descrição } \\
\hline $\begin{array}{c}\text { Programa Sócio } \\
\text { do Interior } \\
\text { "Avanti”" }\end{array}$ & $\begin{array}{l}\text { Modelo } \\
\text { Contratual } \\
\text { fazer parte do quadro de associados do clube, o Palmeiras oferece a opção } \\
\text { Sócio do Interior. Nesta modalidade, o sócio paga R\$ 374,50 por ano para } \\
\text { manter seu título, uma taxa única de R\$ 32,00 para a confecção da primeira } \\
\text { carteirinha e tem direito a frequentar a sede social (Conjunto Aquático, } \\
\text { sauna, quadras poliesportivas, Parquinho e restaurantes) ou o clube de campo } \\
\text { por 30 dias consecutivos no ano. }\end{array}$ \\
\hline $\begin{array}{c}\text { Programa de } \\
\text { "Avantio Torcedor: }\end{array}$ & $\begin{array}{l}\text { Modelo } \\
\text { Contratual }\end{array}$ & $\begin{array}{l}\text { Avanti Palmeiras é o programa de sócio torcedor da Sociedade Esportiva } \\
\text { Palmeiras. Estamos aqui desde 2012 para aproximar cada vez mais a torcida } \\
\text { que canta e vibra e o maior campeão do Brasil. Todo sócio Avanti contribui } \\
\text { diretamente para o futebol do Palmeiras e tem acesso a benefícios e } \\
\text { descontos. Juntos, podemos ir mais longe na busca de novas conquistas }\end{array}$ \\
\hline
\end{tabular}

Fonte: Elaborado pelos autores com base nos resultados da pesquisa (2018).

De acordo com o próprio site do Palmeiras, percebe-se um importante enfoque para o marketing de relacionamento: "O Avanti é um programa diferenciado, com benefícios perceptíveis, objetivando sempre trazer o Palmeiras mais perto do palmeirense" (SE PALMEIRAS, 2018).

Indo ao encontro dos conceitos de Modelo Contratual propostos por Santos (2015) e Zenone (2017), os Programa Sócio do Interior “Avanti” e Sócio Torcedor "Avanti”, tem características parecidas, mas uma segmentação diferente: enquanto o Sócio Torcedor engloba a maior parte dos torcedores da capital, que conseguem ir em mais jogos durante o ano, o 
sócio do interior busca os Palmeirenses que vão pouco aos jogos, incluindo estes nos sócios do clube social, para que tenham experiências diferentes quando vão à capital.

Grande parte do sucesso do Programa "Avanti", está associado ao estádio próprio do Palmeiras: o Allianz Parque Arena. A capacidade do estádio é de 55000 torcedores aproximadamente. Entretanto, o Palmeiras possui um contingente de 1.300.000 torcedores somente em São Paulo. Desta forma, os benefícios trazidos pelo Programa de Sócio Torcedor, como a prioridade em ingressos e a abertura para compra antecipada, auxilia os sócios torcedores na frequência aos estádios, sendo que o torcedor perceba que o valor pago pelo programa é pequeno perto dos benefícios, seguindo a teoria do modelo contratual.

As estratégias de marketing de relacionamento propostas pela Sociedade Esportiva Palmeiras estão associadas ao programa de Sócio Torcedor "Avanti". Os planos oferecidos são: "Diamante", "Platina", "Ouro", "Prata Superior", "Prata" e "Bronze".

\subsection{Comparação das ações de marketing de relacionamento}

Conforme exposto no último tópico, pode-se citar diversas ações dos clubes estudados relacionadas com o marketing de relacionamento. Apresenta-se no quadro abaixo a comparação entre as ações de marketing de relacionamento entre os quatro clubes estudados.

Quadro 6 - Quadro comparativo: Ações de Marketing de Relacionamento

\begin{tabular}{|c|c|c|c|c|}
\hline Classificação & Flamengo & Corinthians & São Paulo & Palmeiras \\
\hline $\begin{array}{c}\text { Modelo Contratual }- \\
\text { Programa Sócio Torcedor }\end{array}$ & $\mathrm{X}$ & $\mathrm{X}$ & $\mathrm{X}$ & $\mathrm{X}$ \\
\hline $\begin{array}{c}\text { Modelo contratual para o } \\
\text { Clube }\end{array}$ & $\mathrm{X}$ & & & \\
\hline Produto Experiência & & & $\mathrm{X}$ & \\
\hline Modelo educacional & & $\mathrm{X}$ & & \\
\hline Modelo de recompensa & & $\mathrm{X}$ & & \\
\hline $\begin{array}{c}\text { Modelo de valor agregado } \\
\text { ou adicional }\end{array}$ & & & $\mathrm{X}$ & \\
\hline
\end{tabular}

Fonte: Elaborado pelos autores com base nos resultados da pesquisa (2018).

O quadro acima mostra uma comparação entre os clubes estudados, de acordo com os modelos de estratégias de relacionamento usadas. O Corinthians e o São Paulo utilizam outras estratégias diferentes do modelo contratual, buscando uma maior prospecção e fidelização dos seus torcedores, além de oferecer a estes momentos inesquecíveis a partir do Produto Experiência fornecido pelo São Paulo e o Modelo Educacional do "Loko da Fiel" proposto pelo Corinthians.

Outra particularidade do Corinthians está no modelo de Recompensa proposto pelo Programa "Louco por Pontos". Diferentemente dos outros clubes, que possuem a distribuição dos pontos como benefício do programa sócio torcedor, o Corinthians considera importante oferecer para todos os torcedores essa possibilidade, com o objetivo de atender uma maior quantidade de produtos vendidos e consequentemente impulsionar as receitas.

O São Paulo, por sua vez, utiliza o seu Patrocinador Master para fidelizar os seus torcedores. Desta forma, a estratégia utilizada é o modelo de valor agregado ou adicional, em que o objetivo é agregar um alto valor para o cliente a partir de parceria entre empresas. $\mathrm{O}$ 
Banco Inter, além dos próprios benefícios oferecidos ao São Paulo, atua em todos os programas de marketing de relacionamento propostos pelo clube.

A partir do quadro pode-se perceber que Programa Sócio Torcedor, dentro da classificação do modelo contratual é o mais comum entre os clubes. Desta forma, é nítida a busca dos clubes por novas formas de angariar recursos para manter as atividades, em troca do fornecimento de várias possibilidades para os seus torcedores ("clientes" em potencial). Dentro dos valores, pode-se destacar:

O Palmeiras arrecadou em 2017 aproximadamente 74 milhões com os torcedores em seu Estádio, o Flamengo arrecadou o valor de 62 milhões, o São Paulo arrecadou o valor de 26 milhões e o Corinthians não publicou o resultado em seu DRE. Com relação aos sócios torcedores, o valor arrecadado está no quadro 7 (SE PALMEIRAS, 2018; FLAMENGO, 2018; CORINTHIANS, 2017; SÃO PAULO FC, 2017).

Acredita-se que o uso do modelo contratual como ação mais comum aos clubes estudados deve-se a particularidade desses negócios. Como clubes de futebol, sendo parte do universo esportivo, o marketing de relacionamento não tem como objetivo evitar que o cliente vá para o concorrente, mas sim, angariar recursos para o clube e tornar o torcedor um cliente lucrativo.

Ao contrário da maior parte das empresas, que visa maior fidelização e o relacionamento próximo com o seu cliente para evitar que esse compre em seus concorrentes, o caso dos clubes de futebol não tem a preocupação que seu torcedor mude para outro time. Um Palmeirense, por exemplo, não se tornará corintiano porque os programas do Corinthians têm mais vantagens e alcançam mais públicos. O P de Paixão do marketing esportivo explica bem essa particularidade, na qual diferente dos casos da maioria das empresas, as organizações do ramo esportivo lidam com a paixão e amor do torcedor as suas marcas.

Nesse sentido, o principal objetivo do marketing de relacionamento para o universo esportivo é converter o torcedor comum em um torcedor lucrativo. Assim, justifica-se que a maioria das ações estejam relacionadas ao modelo contratual, que possibilita rentabilidade para o clube.

Dentre as ações, pode-se visualizar algumas diferenças entre os clubes. O São Paulo, por exemplo possui maior transparência em seus dados, divulgando todas as ações do clube além do Programa de Sócio Torcedor. O Flamengo tem foco maior no preço e na facilidade na compra de ingressos, isso é possível pois o Flamengo sedia seus jogos no Estádio com maior capacidade em números do Brasil. O Corinthians além dos benefícios em ingressos, fornece outras formas de vantagens, como o programa próprio de pontos e lugares cativos para os sócios-torcedores de acordo com o plano.

Sobre as outras ações ressalta-se a diferenciação do Corinthians, que não só utiliza o modelo contratual, mas tem também o modelo educacional e o modelo de recompensa como estratégias de relacionamento. A variedade de modelos de marketing de relacionamento utilizada pelo Corinthians não é percebida nos outros clubes estudados.

O São Paulo busca experiências novas aos seus sócios a partir dos "Produtos Experiência" que consegue prospectar recursos para o clube tendo enfoque no "P" de paixão, em que troca o dinheiro (preço) por momentos inesquecíveis e de difícil precificação, o que reforça a importância do valor percebido pelo cliente (torcedor).

Após verificar as diversas ações executadas pelos clubes ao utilizar o marketing de relacionamento para prospectar, fidelizar e manter um relacionamento duradouro com os seus torcedores, foi possível identificar estratégias desenvolvidas em comum e outras diferenciadas, visando uma maior arrecadação através dos programas do sócio torcedor. 
Tendo em vista que os programas de Sócio Torcedor, de modelo contratual são as únicas ações comuns a todos os clubes e considerando a relevância de rentabilidade desses programas, buscou-se comparar também os benefícios oferecidos pelos clubes em cada programa sócio torcedor (Quadro 7). Nesse quadro é possível verificar quais ferramentas mais se repetem entre os clubes pesquisados no programa de sócio torcedor, bem como quais são pouco exploradas.

Quadro 7 - Comparação dos benefícios entre os Programas Sócio Torcedor

\begin{tabular}{|c|c|c|c|c|}
\hline Benefícios/Clubes & Flamengo & Corinthians & São Paulo & Palmeiras \\
\hline Descontos em Ingressos & $\mathrm{X}$ & $\mathrm{X}$ & $\mathrm{X}$ & $\mathrm{X}$ \\
\hline Pré-venda Exclusiva & $\mathrm{X}$ & $\mathrm{X}$ & $\mathrm{X}$ & $\mathrm{X}$ \\
\hline Descontos na Loja Oficial & $\mathrm{X}$ & $\mathrm{X}$ & $\mathrm{X}$ & $\mathrm{X}$ \\
\hline Experiências & $\mathrm{X}$ & $\mathrm{X}$ & $\mathrm{X}$ & $\mathrm{X}$ \\
\hline Redes de Descontos & $\mathrm{X}$ & $\mathrm{X}$ & $\mathrm{X}$ & $\mathrm{X}$ \\
\hline Posto de Venda Exclusivo (Físico) & & $\mathrm{X}$ & & \\
\hline Compra de Ingressos Online & $\mathrm{X}$ & $\mathrm{X}$ & $\mathrm{X}$ & $\mathrm{X}$ \\
\hline Participação em Concursos e Promoções & & $\mathrm{X}$ & $\mathrm{X}$ & \\
\hline Inclusão de Dependentes & $\mathrm{X}^{*}$ & $\mathrm{X}$ & & $\mathrm{X}$ \\
\hline Cadeira Personalizada & & $\mathrm{X}$ & & \\
\hline Compra de Estacionamento & & $\mathrm{X}$ & & \\
\hline Acesso Exclusivo & & $\mathrm{x}$ & & \\
\hline Programas de Viagens & & & $\mathrm{X}$ & \\
\hline Programa Escolinha de Esportes & $\mathrm{x}$ & $\mathrm{x}$ & $\mathrm{X}$ & $\mathrm{x}$ \\
\hline Clube de Vantagem (pontos) & $\mathrm{x}$ & $\mathrm{x}$ & $\mathrm{X}$ & $\mathrm{x}$ \\
\hline Programa de Fidelidade & $\mathrm{x}$ & $x^{*}$ & $\mathrm{X}$ & $x^{*}$ \\
\hline Cartão em Forma de Débito & $\mathrm{x}$ & & & \\
\hline Movimento por um futebol melhor (AMBEV) & & $\mathrm{x}$ & $\mathrm{X}$ & $\mathrm{x}$ \\
\hline Torcedor de Fora do Estado de Origem & $\mathrm{x}$ & & $\mathrm{X}$ & $\mathrm{x}^{* 1}$ \\
\hline Revista Digital & & & & $\mathrm{x}$ \\
\hline Embaixadas em Outros Estados & $\mathrm{x}$ & $x^{*}$ & $\mathrm{X}$ & $\mathrm{x}$ \\
\hline Estádio Próprio & & $\mathrm{x}$ & $\mathrm{X}$ & $\mathrm{x}$ \\
\hline Número de Sócios Torcedores & $92 \mathrm{mil}$ & $117 \mathrm{mil}$ & 154 mil & $130 \mathrm{mil}$ \\
\hline Valor Arrecadado com Sócio Torcedor & 43 milhões & 7 milhões & 10 milhões & 47 milhões \\
\hline Valor (Plano mais alto) & 199 reais & 720 reais & 489 reais & 649 reais \\
\hline
\end{tabular}

Fonte: Elaborado pelos autores com base nos resultados da pesquisa (2018).

Destaca-se, a partir deste quadro, que as ações mais executadas pelos clubes relacionadas ao marketing de relacionamento são os descontos em ingressos, a pré-venda exclusiva de ingressos, os descontos nas lojas oficiais do clube, o fornecimento de novas experiências (engloba visitas ao CT, conhecer jogadores, participar do dia a dia do clube, frequentar centros de treinamento, etc), as redes de descontos e o clube de vantagens (acúmulo de pontos para trocas).

\footnotetext{
${ }^{1}$ Os valores em * referem-se aos benefícios que ainda não foram implantados completamente ou começam a não ser oferecidos pelos clubes.
} 
Um ponto interessante é o "Programa de Fidelização" dos torcedores. O Flamengo e o São Paulo estão buscando uma maior fidelização dos seus sócios torcedores, assim como Kotler (2014) e Zenone (2017) dizem sobre o marketing de relacionamento. Os clubes buscam fornecer benefícios além do plano de sócio torcedor, visando uma maior adimplência e consequentemente números financeiros mais interessantes, através da assiduidade do torcedor.

O marketing de relacionamento é caracterizado por procurar prospectar, fidelizar e promover ações de propaganda para tornar o cliente o vendedor principal da empresa. Neste sentido, aumentar a rede de dependentes e consequentemente de sócios torcedores, pode ampliar a prospecção de novos sócios e fidelizar o sócio já existente pela sua satisfação.

Comparando o valor arrecadado pelos clubes com os números de torcedores indicados na pesquisa da AMBEV (2018), pode-se dizer que o sócio torcedor flamenguista foi o que mais gastou com o seu clube, tendo um gasto mensal de 38,94, o sócio torcedor do Palmeiras gastou o valor de $\mathrm{R} \$ 30,13$ por torcedor/mensal, o sócio torcedor são paulino gastou 5,41 reais mensais, enquanto o sócio torcedor corinthiano teve um gasto de $\mathrm{R} \$ 4,99$. Os valores não conseguem refletir totalmente a realidade pela quantidade de inadimplentes e promoções, nivelando por baixo o valor gasto por cada sócio torcedor, além das despesas que cada sócio torcedor promove para o clube.

É interessante quando se fala sobre a possibilidade de perda de clientes no futebol, quando sabemos que a probabilidade de um torcedor mudar de clube é muito pequena. Entretanto, conforme diz Melo Neto (2013) e associando com o que fala Kotler e Armstrong (2014) no quadro de Preço x Benefícios, existe uma possibilidade grande do torcedor se desinteressar pelo esporte, fazendo com que não exista uma fidelização e o torcedor passe a não contribuir com o clube, prejudicando os índices financeiros e travando o crescimento do esporte.

\section{Conclusão}

Através dos resultados apresentados, pôde-se identificar as ações de marketing de relacionamento utilizadas pelos clubes, classifica-las conforme a teoria da área e comparar as ações entre os clubes, cumprindo o objetivo geral e os objetivos específicos propostos inicialmente no estudo.

Dentre os resultados encontrados, destaca-se que o programa de sócio torcedor é o carro chefe dos clubes estudados. A maioria das ações de marketing de relacionamento estão voltadas para o modelo contratual destes programas, encontrando em lojas parceiras inclusive auxílio para maior prospecção de torcedores.

O Futebol é uma área extremamente peculiar e de números difíceis de mensurar. Teoricamente, não existe a possibilidade de o torcedor sair de um clube para passar a torcer para a "concorrência", só em casos extremamente raros. Entretanto, existe a possibilidade do desinteresse pelo esporte e principalmente, descaso com as ações do clube de coração.

A partir deste trabalho fica nítida a importância de entender a teoria do marketing de relacionamento para outros contextos, não só para os modelos de business mais comuns. $\mathrm{O}$ esporte com o acréscimo de um novo "P", o Paixão, além de estratégias de gestão em muitas situações ditas amadoras, traz um novo paradigma para aplicar os conceitos de marketing de relacionamento, visando entender mais puramente os métodos de prospecção e fidelização, sem ter a concorrência da forma como conhecemos.

Este trabalho traz informações relevantes para outros estudos no âmbito de Marketing de Relacionamento, Marketing Esportivo e Gestão Esportiva. Desta forma, o diagnóstico 
auxiliará para pesquisas relacionadas ao comportamento do consumidor, ao nível de receitas e despesas dos clubes de futebol e incisivamente no processo de gestão esportiva, tendo nessas áreas a possibilidade de um estudo mais completo e robusto, com informações extremamente significativas para a sociedade. Diante da necessidade de uma maior profissionalização do futebol no Brasil, pesquisas como essa no âmbito esportivo, auxiliariam para uma prática mais eficaz de gestão, a partir de números e relatos teóricos.

Inicialmente, o presente trabalho contaria com o estudo de cinco clubes, sendo o quinto o Clube de Regatas Vasco da Gama. Entretanto, a partir da análise dos resultados, ficou nítida a pequena transparência do clube, tendo os balancetes mais atualizados em $2013 \mathrm{e}$ uma inconsistência nos programas de marketing de relacionamento, neste caso, faz-se necessária outras metodologias para extrair informações mais precisas dos clubes, ou seja, em futuras pesquisas, sugere-se a exploração das ações com esses e outros clubes a partir de dados primários e entrevistas com os diretores do clube, possibilitando maior exploração dos objetivos e características das ações.

\section{Referências}

ALMEIDA, M. I. S.; COELHO, R. L. F.; OLIVEIRA, D. S.; CAMARGO, A.; SAVIOLI, P. Sales-based Brand Equity as a Performance Driver in 'The Country of Soccer' . Revista de Administração Contemporânea, v. 24, n. 2, p. 134-150, 2020.

AMBEV. Movimento por um Futebol Melhor. 2018. Disponível em: <https://www.futebolmelhor.com.br/clubes/>. Acesso em 30.10.18

BDO, $11^{\circ}$ Valor das Marcas dos Clubes Brasuleiros. 2018. Disponível em: $<$ https://www.bdo.com.br/pt-br/publicacoes/noticias-em-destaque/11\%C2\%BA-valor-dasmarcas-dos-clubes-brasileiros>. Acesso em 18.02.2020

BERRY, L. L., PARASURAMAN, A. Serviços de marketing. 3. ed. São Paulo: Maltese, 1995.

CORINTHIANS. Estatuto Social. 2017. Disponível em: <https://esm31.websiteseguro.com/Estatuto2017.pdf〉. Acesso em 15/11/2018

CORINTHIANS. Orçamento 2018. Disponível em <https://cdn.corinthians.com.br/wpcontent/uploads/2015/01/10153227/Ciclo-de-Planejamento-2018_site.pdf> Acesso em $18 / 11 / 2018$

DATAFOLHA, I.P. Flamengo e Corinthians seguem na liderança de torcidas. 2018. Disponível em: <http://datafolha.folha.uol.com.br/opiniaopublica/2018/04/1964748flamengo-e-corinthians-seguem-na-lideranca-de-torcidas.shtml>

DICIONÁRIO. Origem da Palavra. 2018. Disponível em: <http://origemdapalavra.com.br/palavras/esporte/>. Acesso em 09/12/2018

FLAMENGO. Estatuto Social. 2017. Disponível em: <https://fla-bucket-s3us.s3.amazonaws.com/public/arquivos/estatuto.pdf>. Acesso em 15/11/2018 
Marketing de relacionamento na gestão do futebol: identificação e comparação das ações em quatro

FLAMENGO. Governança Corporativa. 2018. Disponível em:

$<\mathrm{http}: / / \mathrm{www}$. flamengo.com.br/transparencia/governanca-corporativa $>$. Acesso em $15 / 11 / 2018$

GIL, A. C. Como elaborar projetos de pesquisa. São Paulo, v. 5, n. 61, p. 16-17, 2002.

GLOBO ESPORTE. Fifa diz que primeira rodada da Copa bateu recordes de audiência na TV. 2014. Disponível em: <http://globoesporte.globo.com/futebol/copa-domundo/noticia/2014/06/fifa-diz-que-primeira-rodada-da-copa-bateu-recordes-de-audienciana-tv.html>. Acesso em 20/11/2018

GLOBO ESPORTEb. Fifa divulga números de audiência da Copa de 2014: mais de 1 bi na final. 2015. Disponível em <http://globoesporte.globo.com/futebol/copa-domundo/noticia/2015/12/fifa-divulga-numeros-de-audiencia-da-copa-de-2014-mais-de-1-bina-final.html>. Acesso em 20/11/2018

KANTAR IBOPE. Audiência de TV de todos os jogos da Copa do Mundo. 2018. Disponível em: <https://www.kantaribopemedia.com/copadomundo/dados-de-audiencia-da-copa-domundo-2018/> Acesso em: 20/02/2020

INTERNACIONAL. Site Oficial. 2018. Disponível em: <https://www.internacional.com.br> . Acesso em 25/11/2018

ITAU, Analise dos Clubes Brasileiros de Futebol, 2017

ITAU, Analise dos Clubes Brasileiros de Futebol, 2018

KOTLER, P. \& ARMSTRONG, G. Princípios de Marketing. 15 ed. São Paulo: Pearson/Prentice, 2014

KOTLER, P. AMSTRONG, G. Princípios de marketing. São Paulo: Pearson Prentice Hall, 2008

LOKO DA FIEL. Loko da Fiel. 2018. Disponível em: < https://www.lokodafiel.com.br/> . Acesso em: 20 nov. 2018.

MARCONI, M. A.; LAKATOS, E. M. Fundamentos de metodologia científica. 5. ed.-São Paulo: Atlas, 2003.

MATTAR, M. Na trave: o que falta para o futebol brasileiro ter uma gestão profissional. Elsevier Brasil, 2017

McKENNA, R. Marketing de relacionamento: estratégias bem sucedidas para a era do cliente. Rio de Janeiro: Campus, 1992

MELO NETO, F. P. Marketing Esportivo: O esporte como ferramenta do marketing moderno. Rio de Janeiro: BestSeller, 2013.

MORGAN, M. J.; SUMMERS, J. Marketing Esportivo. São Paulo: Thomson Learning, 2008. 
PITTS, B. G; STOTLAR, D. Fundamentos de Marketing Esportivo. São Paulo: Phorte, 2002.

SANTOS, A. S. dos. Marketing de Relacionamento. São Paulo: Pearson, 2015

SÃO PAULO FC. Estatuto Social e Sócio Torcedor. 2017. Disponível em: <http://www.saopaulofc.net> . Acesso em 15/11/2018

SE PALMEIRAS. Estatuto Social, Sócio Torcedor e Demonstrativo Financeiro. 2018.

Disponível em:

<http://www.palmeiras.com.br/public/upload/documento/uploads/documento_590.pdf>. Acesso em 15/11/2018

SILVEIRA, M.; ASSUMPÇÃO, J.J. O marketing de relacionamento como alternativa em mercados competitivos. 2010.

SOUZA, A.; LUBISCO, M. Estratégia de marketing de relacionamento com seus sócios: a filosofia Alma Colorada. 2006.

SPFC. Relatório de Gestão. 2018. Disponível em:

<http://www.saopaulofc.net/media/183637/spfc_relatorio_web1.pdf> Acesso em $20 / 11 / 2018$

SPORT CLUB CORINTHIANS PAULISTA. Fiel Torcedor. 2018. Disponível em: $<$ https://www.fieltorcedor.com.br> Acesso em 06/11/2018

STAREPRAVO, F.A. et al. Esporte universitário brasileiro: uma leitura a partir de suas relações com o Estado. Revista Brasileira de Ciências do Esporte, v. 31, n. 3, 2010.

VANCE, P et al. Gestão do Esporte: Casos brasileiros e internacionais. 1.ed. Rio de Janeiro: LTC, 2015

ZENONE, L. C. Fundamentos de Marketing de Relacionamento. Fidelização de Clientes e Pós-Venda. 2ed. São Paulo: Atlas, 2017. 